\title{
Special issue on the 11th conference on naturalistic decision making
}

\author{
Hervé Chaudet • Liliane Pellegrin • Nathalie Bonnardel
}

Received: 14 February 2015/ Accepted: 16 February 2015/Published online: 27 February 2015

(C) Springer-Verlag London 2015

\section{Introduction}

The naturalistic decision-making (NDM) approach deals with how humans make decisions in natural settings, especially professional situations, which can be difficult to reproduce in experimental laboratory studies. NDM explores collaboration and cooperation both between humans, and between humans and systems, as well as situations of diagnosis, planning, supervision, and control processes. Basically, decision researchers focus on the analysis of humans at work and their interactions with systems in context, including both environmental and social dimensions. Since the movement was founded, more than 20 years ago, several models of decision making have been developed, each offering a fresh view on how humans perform complex cognitive functions to accomplish situated activities.

This very different way of studying human interactions in modern work environments has given rise to a worldwide research community sharing the same issues and a common theoretical background, and relying on ecological models of decision making (Brehmer 1992; Endsley 1995; Hutchins 1995; Rasmussen et al. 1994); models of

H. Chaudet $(\square)$

SESSTIM - UMR 912, Aix-Marseille Université, Marseilles, France

e-mail: 1hcp@acm.org

\section{Pellegrin}

CESPA, Service de Santé des Armées SESSTIM - UMR 912,

Aix-Marseille Université, Marseilles, France

N. Bonnardel

PsyCLE EA 3273, Aix-Marseille Université, Aix-en-Provence, France intelligence, perception, and action as mental models (Johnson-Laird 1983); and activity theory (Engeström 1999; Kuutti 1996; Nardi 1996). Looking further back, the field of naturalistic decision making can be seen to have its historical roots in the ground-breaking work of Vygotsky and Leont'ev (Leont'ev 1978; Leont'ev and Luria 1968), and even Piaget's intelligence theory (Piaget 1972, 1977).

The NDM approach, which is predicated upon a strong relationship between application fields, research, and models of complex cognitive tasks, is responsible for a now well-established definition of decision making (Klein et al. 1993): "eight important factors characterize decision making in naturalistic settings, but frequently are ignored in decision-making research. It is not likely that all eight factors will be at their most difficult levels in any one setting, but often several of these factors will complicate the decision task.

- Ill-structured problems,

- Uncertain dynamic environments,

- Shifting, ill-defined, or competing goals,

- Action/feedback loops,

- Time stress,

- High stakes,

- Multiple players,

- Organizational goals and norms"

All these contextual constraints and their dynamics can influence complex expert decisions. Individual and collective resources are allocated to understanding the situation, and once it has been understood, a course of action is implemented (Lipshitz et al. 2001). Background knowledge (e.g., experience, roles, and scripts) can be regarded as a key factor for making decisions (Lipshitz et al. 2001), but the skills and knowledge used in one context do not necessarily transfer to another (Singley and Anderson 
1989). In addition, background knowledge or example behaviors may be limited, or even nonexistent, in some cases (Brookfield 1987). Individuals may therefore find themselves faced with unfamiliar real-world problems that require a degree of creativity - creativity being defined in terms of novelty and the ability to apply a new solution to the task or situation at hand (Sternberg and Lubart 1999)_although creative activities may be particularly difficult to undertake in natural environments, mainly owing to time constraints.

Because NDM studies human performances in situations characterized by time pressure, uncertainty, vague goals, high stakes, team and organizational constraints, changing conditions, and varying amounts of experience, it has become a markedly interdisciplinary field, drawing researchers from many different areas.

The most frequent application fields are the following:

- Complex and risky industrial systems (nuclear, chemical, and other complex industrial systems), transport (e.g., air, sea, and rail);

- Health care (e.g., intensive care, surgery, and epidemiological surveillance);

- Defense and security (command and control).

Because of the strong interactions between human operators and complex systems in our modern society, NDM is also interested in the design and use of the technological and digital environments (information systems, decision support systems, communication systems) used by professionals in the course of their control, supervision, and decision-making activities.

\section{The NDM conference series}

Ever since the NDM approach was founded, international conferences have taken place every 2 years, alternating between Europe and the United States. NDN1 (Dayton, $\mathrm{OH}$ ) was organized by the founding group (Klein et al. 1993) in 1989 and set the stage for expanding the study of problem-solving and decision making. During these conferences, keynotes and presentations introduce the latest research advances and describe field experiences, encouraging participants to trade ideas and exchange opinions. They create scientific forums that are simultaneously based upon theory, method, and practice.

NDM11, the most recent conference, was held in Marseilles in May 2013. The main topics of this conference highlighted the following challenges:

- The ongoing development of sociotechnical systems, in particular their increasing complexity and the impact of this complexity on human activities;
- Teamwork in complex organizations and situations, and in a variety of fields (e.g., healthcare, transport, defense, and complex industries);

- Models of expertise and teamwork in the management of critical and crisis situations;

- Development of decision support systems, command, and control systems engineering, control of dynamic systems, alarm, and emergency systems;

- New ways of learning collective and individual skills and expertise based on exercises, simulation, and "serious games";

- System-aided analysis and understanding of new or emergent situations (sense-making), and its impact on decision making in complex sociotechnical systems;

- Innovation and creativity in naturalistic decision making, creative decisions.

Thirty-nine papers were submitted to NDM11, from which the Scientific Committee selected 22 papers for oral presentation on the basis of reviewers' recommendations (selection rate: $56.5 \%$ ). These papers, essentially research studies and practical applications, covered various application fields, such as health care, transport, and defense, but also sport, video game playing, security, and government actions (Table 1). They were illustrative of the main NDM topics such as judgment and decision making, situation awareness, uncertainty, and sense-making, with a focus on individual and team activities intended to manage complex situations (see Table 1).

\section{The papers in this special issue}

The papers chosen for this special issue illustrate the diversity of expert decision making (bushfires, sport, nuclear power plants, police) and highlight current and emerging topics of interest for the NDM community:

- Sense-making, metacognition;

- Coordination in decision making, collective decisions, human, and human-machine teamwork;

- Emotion in expert decision making;

- Adaptation to innovative technologies.

These seven research papers represent a range of application fields.

Leena Norros et al. are the authors of the first paper, entitled Operators' orientations to procedure guidance in NPP process control. Through an oversight, this paper has been published separately in volume 16 number 4 , but it rightly belongs in this special section. In the context of organizational resilience, this paper addresses the problem of the balance between operators' autonomy and procedure 
Table 1 Distribution of papers accepted for NDM11

\begin{tabular}{|c|c|c|c|c|c|c|c|}
\hline \multicolumn{2}{|l|}{ Paper types } & \multicolumn{2}{|l|}{ Application fields } & \multicolumn{2}{|l|}{ Topics } & \multicolumn{2}{|l|}{ Research areas } \\
\hline Research/experimental & 11 & Defense & 7 & Judgment and decision making & 9 & Decision making & 7 \\
\hline Practical application & 9 & Education and training & 6 & $\begin{array}{l}\text { Cognitive field research and cognitive task } \\
\text { analysis }\end{array}$ & 8 & $\begin{array}{l}\text { Situation awareness/situation } \\
\text { assessment }\end{array}$ & 4 \\
\hline \multirow[t]{7}{*}{ Theory and modelling } & 2 & Security & 2 & Macrocognition & 2 & Sense-making & 3 \\
\hline & & Health & 2 & $\begin{array}{l}\text { Team and organizational factors in complex } \\
\text { cognitive activity }\end{array}$ & 2 & Learning and training & 2 \\
\hline & & $\begin{array}{l}\text { Earth and atmospheric } \\
\text { sciences }\end{array}$ & 1 & Human-centered and work-centered design & 1 & Coordination & 2 \\
\hline & & Government and law & 1 & & & Command and control & 2 \\
\hline & & Engineering & 1 & & & Uncertainty management & 1 \\
\hline & & Transport & 1 & & & Mental models & 1 \\
\hline & & $\begin{array}{l}\text { Arts (fine and } \\
\text { performing) }\end{array}$ & 1 & & & & \\
\hline
\end{tabular}

guidance in decision making. The authors suggest that a balance can be struck through the "intelligent use of procedures" supported by the operator's sense making in situations that require actions.

Design for responsibility: Safeguarding moral perception via a partnership architecture, by Tjerk de Greef and Alex Leveringhaus, is the second paper. These authors explore the effects of machine autonomy and physical distance on moral perceptions during human decision making, a point that is particularly critical with the use of advanced warfare technologies. They reposition the human within a partnership paradigm where man and machine work concurrently within the bounds of a working agreement. The objective is to ensure that machine usage is safe and does not undermine human decision capacities and morality.

The third paper is by Lorenzo Luini and Francesco Marucci and tackles the impact of emotion during decision making in threatening situations. In Prediction-confirmation hypothesis and affective deflection model to account for split-second decisions and decision-making under pressure of proficient decision-makers, the authors present an example of an experimental study in a NDM situation. The study contrasts unskilled participants with experienced police officers, looking at how threats and other stimuli induce different affective states, and examining their effect on performance during a First-Person Shooting Task. Results showed that the police officers were better at controlling the effects of arousing stimuli and negative affect states, but with longer latencies exposing them to adverse effects.

The next paper is by Anne-Claire Macquet and Koffi Kragba and is entitled What makes basketball players continue with the planned play or change it? A case study of the relationships between sense-making and decision- making. Players use team action plans to coordinate their efforts during a game situation. However, these situations are highly dynamic and require frequent plan changes to cope with new risks and conditions. This paper deals specifically with the sense-making process that leads to plan changes during a game.

Patrick K. Belling et al. are the authors of the fifth paper, entitled The effect of time constraint on anticipation, decision-making, and option-generation in complex and $d y$ namic environments. This paper is also about sport, and the study it describes allowed the authors to analyze option generation under time pressure and compare the use of two heuristics, the Long-Term Working Memory (LTWM) mechanism and the Take-The-First heuristic, during decision making in team sports. The experiment explicitly manipulated time pressure and showed that time constraint induces a shift toward the use of the LTWM mechanism.

In the paper Exploring compatible and incompatible transactions in teams, Linda J. Sorensen and Neville Stanton describe an exploratory study focusing on the impact of schemas-in the sense of cognitive structures and processes-within team communication that can explain patterns of distributed situation awareness in teams. This paper investigates the presence of team schemata observed in the communication data between players during a strategy game. The distributed situation awareness approach can be seen as the result of previous experience and knowledge that are memorized as schema structures by each team member and shape their interactions with the world.

The last paper is by Stephan Takken and William Wong and is entitled In tactile reasoning: Hands-on vs handsoff-what's the difference? The authors sought to determine whether direct manipulation of information by means of objects in a graphical user interface influences 
performance on a sense-making task, enhancing the user's reasoning ability. Results of an experiment revealed better analytical reasoning performances in the hands-on group than in the hands-off one.

Acknowledgments We are grateful to the reviewers who carefully analyzed the submissions and provided valuable comments and suggestions to the authors: Françoise Anceaux, Christine Chauvin, Françoise Darses, Rhona Flin, Anne-Claire Macquet, Leena Norros, Neville Stanton, Peter Thunholm, Agnès Van Daele, William Won, and Paul Ward. We also thank Gary Klein for his support and Carlo Cacciabue for helping us to prepare this special issue.

\section{References}

Brehmer B (1992) Dynamic decision making: human control of complex systems. Acta Psychol 81:211-241

Brookfield SD (1987) Developing critical thinkers. Jossey-Bass, San Francisco

Endsley MR (1995) Toward a theory of situation awareness in dynamic systems. Hum Factors 37(1):32-64

Engeström Y (1999) Activity theory and individual and social transformation. In: Engeström Y, Miettinen R, Punamäki R-L (eds) Perspectives on activity theory. Cambridge University Press, Cambridge, pp 19-38

Hutchins E (1995) Cognition in the wild. MIT Press, Cambridge

Johnson-Laird PN (1983) Mental models: towards a cognitive science of language, inference, and consciousness. Cambridge University Press, Cambridge
Klein G, Orasanu J, Calderwood R, Zsambok CE (1993) Decision making in Action-Models and methods. Ablex Publishing, New York

Kuutti K (1996) Activity theory as a potential framework for humancomputer interaction research. In: Nardi BA (ed) Context and consciousness: activity theory and human-computer interaction. MIT Press, Cambridge, pp 17-44

Leont'ev AN (1978) Activity, consciousness, personality. Prentice Hall, Englewood Cliffs

Leont'ev AN, Luria AR (1968) The psychological ideas of L. S. Vygotskii. In: Wolman BB (ed) Historical roots of contemporary psychology. Harper \& Row, New York, pp 338-367

Lipshitz R, Klein G, Orasanu J, Salas E (2001) Focus article: taking stock of naturalistic decision making. J Behav Decis Mak $14: 331-352$

Nardi BA (1996) Studying context: A comparison of activity theory, situated action models and distributed cognition. In: Nardi BA (ed) Context and consciousness: Activity theory and humancomputer interaction. MIT Press, Cambridge, pp 35-52

Piaget J (1972) To understand is to invent. Viking Press, New York

Piaget J (1977) The development of thought: equilibration of cognitive structures (trans: Rosen A). Viking Press, New York

Rasmussen J, Pejtersen AM, Goodstein LP (1994) Cognitive systems engineering. Wiley, New York

Singley MK, Anderson JR (1989) The transfer of cognitive skill. Harvard University Press, Cambridge

Sternberg RJ, Lubart TI (1999) The concept of creativity: Prospects and paradigms. In: Sternberg RJ (ed) Handbook of creativity. Cambridge University Press, New York, pp 3-15 